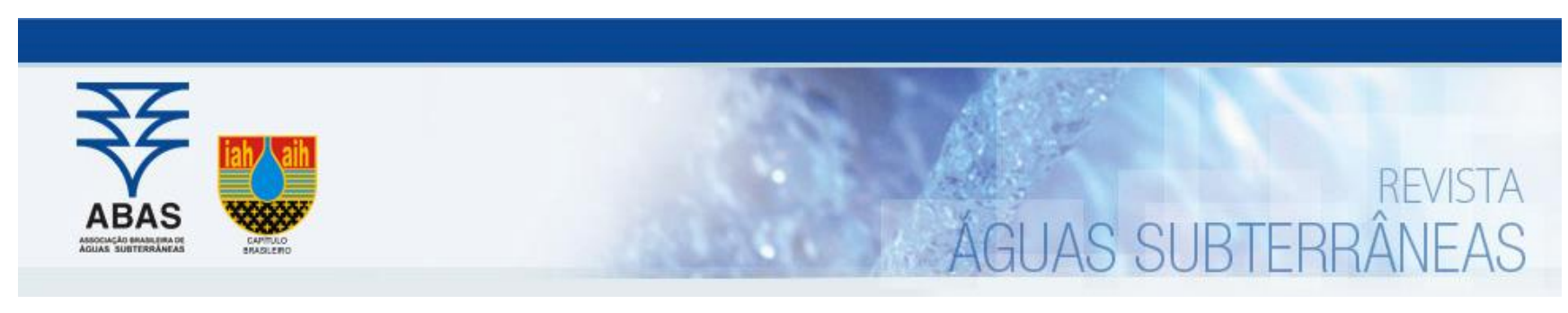

Artigos

\title{
Uso de dados hidrogeofísicos e modelos numéricos como alternativa na otimização de locações de poços em um aquífero não confinado
}

\section{Use of hydrogeophysical data and numerical models as an alternative to optimize well locations in an unconfined aquifer}

\author{
Rafaela da Silva Alves ${ }^{1}$; Leandson Roberto Fernandes de Lucena ${ }^{\circledR}$ \\ 1 Universidade Federal do Rio Grande do Norte (UFRN), Natal, RN \\ $\triangle \underline{\text { alves.rafaelasilva@gmail.com, leandson@geofisica.ufrn.br }}$
}

Palavras-chave:

Aquífero Barreiras.

Falhamentos Neógenos.

Hidrogeofísica.

Espessura saturada.

Modelos numéricos.

\begin{abstract}
$\underline{\text { Resumo }}$
Aquíferos compartimentados por falhas ficam sujeitos às diversas alterações, entre elas a variação de espessuras saturadas e padrões de fluxo. O Aquífero Barreiras, em uma área na região Leste do Estado do Rio Grande do Norte, estruturalmente compartimentado por falhamentos Neógenos, possui uma bateria de 12 poços tubulares instalados no ano de 2011, os quais captam cerca de $750 \mathrm{~m}^{3} / \mathrm{h}$ destinados ao suprimento de água de municípios interioranos. Nesse contexto, o presente artigo aborda a otimização de locações adicionais de poços através do uso alternativo de dados hidrogeofísicos e modelos numéricos, no âmbito de um aquífero estruturalmente compartimentado. A metodologia contou com o uso de modelos geoelétricos inversos 1D, correlação entre perfis litológicos dos poços e seções hidrogeofísicas, destinadas a aprofundar a caracterização da compartimentação estrutural do aquífero, além de um mapa de espessura saturada para guiar as simulações numéricas efetuadas no MODFLOW. 0 mapa de espessura saturada indica que na região oeste da área estão os menores valores deste parâmetro, entre 30 e 40 m. Por outro lado, na região nordeste ocorrem isolinhas de 70 até um máximo de $90 \mathrm{~m}$ de espessura saturada. As simulações numéricas, por sua vez, indicaram que as áreas de grábens relativos são as mais propícias para futuras perfurações. Essas áreas possuem maiores espessuras saturadas podendo, assim, indicar setores com maiores vazões de explotação disponíveis.
\end{abstract}

Abstract

Keywords:

Barreiras Aquifer. Neogene faults. Hydrogeophysics. Saturated thickness.

Numerical model.

Revisão por pares.

Recebido em: 08/12/2020

Aprovado em: 18/02/2021.

\begin{abstract}
Aquifers compartmentalized by faults are subject to several alterations, among which the variation of saturated thicknesses and flow patterns. The Barreiras Aquifer, located in the eastern part of the State of Rio Grande do Norte, is structurally compartmentalized by Neogene faults. This aquifer has a battery of 12 tubular wells installed in 2011 , which capture about $750 \mathrm{~m}^{3} / \mathrm{h}$ destined to the water supply of several municipalities. In this context, this article addresses the optimization of additional well locations through the alternative use of hydrogeophysical data and numerical models, within a structurally compartmentalized aquifer. The methodology used 1D inverse geoelectric models, a correlation between lithological profiles of wells and hydrogeophysical cross-sections, aimed at deepening the characterization of the structural compartmentalization of the aquifer. In addition, the study performed a saturated thickness map to guide the numerical simulations performed in MODFLOW. The saturated thickness map indicates that in the western region exhibits the smallest values of saturated thickness, between 30 and $40 \mathrm{~m}$. On the other hand, there are isolines from 70 to a maximum of $90 \mathrm{~m}$ saturated thickness in the northeast area. Numerical simulations, in turn, indicated that relative grabens areas are the most favorable for future drilling. These areas have the highest saturated thickness, and, thus, being able to indicate sectors with highest exploitation flows available.
\end{abstract}

DOI: http:/dx.doi.org/10.14295/ras.v35i1.29987

\section{INTRODUÇÃO E OBJETIVOS}

A presença de falhas no contexto hidrogeológico torna este meio sujeito a alterações de variação de espessura saturada, no padrão do fluxo subterrâneo, transporte de contaminantes, além de modificações na condutividade hidráulica (JOURDE et al., 2002; BENSE e PERSON, 2006; BALL et al., 2010; WILLI-
AMS et al., 2015).

Fernandes e Rudolph (2001) concluíram em sua pesquisa que fraturas extensionais têm aberturas mais efetivas que àquelas provenientes de movimentos cisalhantes. A abertura das fraturas é considerada, pelos autores, o fator mais importante para aumento ou diminuição da condutividade hidráulica. A presen- 
ça de falhamentos pode desencadear abatimentos ou soerguimentos relativos de blocos estruturais provocando variações negativas ou positivas de espessura saturada. Em caso de variações positivas, este cenário é responsável por maiores rebaixamentos disponíveis e, consequentemente, por maiores vazões de explotação (LUCENA, 2005).

Balsamo e Storti (2010) e Balsamo et al., (2010), em pesquisas realizadas na Bacia Paraíba, revelaram que arenitos em zonas de dano de falhas apresentam fluxo granular dilatador. Desse modo, a presença de fraturas extensionais intergranulares aumenta a porosidade, conectividade entre os poros e a permeabilidade, incrementando a condutividade hidráulica.

O Aquífero Barreiras sempre conviveu com a concepção de que a água era um recurso praticamente infinito, particularmente na região leste do Estado do Rio Grande do Norte, alvo desta pesquisa. Bibliografias consagradas reconhecem a alta potencialidade deste manancial subterrâneo (SERHID, 1998; ANA, 2012), devido a elevada pluviometria da região e seus rios perenes. Este cenário vem se agravando pelo aumento da urbanização e, consequentemente, crescente demanda por recursos hídricos.

$\mathrm{Na}$ área tomada como alvo desse estudo (Figura 1), localizada no município de Nísia Floresta-RN, uma falha bem documen- tada de direção noroeste, particularmente, correspondendo à borda sudoeste de um proeminente graben regional, impõe forte controle estrutural na região (LUCENA, 2005; BEZERRA et al., 2001; NOGUEIRA et al., 2006). Nesta área, acha-se inserida parte de um sistema adutor local, compondo 12 poços produtores e cerca de 36 de monitoramento, executados a partir de 2011 e com base em estudos prévios de disponibilidades. Estudos complementares (SEMARH, 2012), realizados com o intuito de definir condições de explotação dessa captação, definiram uma descarga total de $750 \mathrm{~m}^{3} / \mathrm{h}$, em detrimento aos $900 \mathrm{~m}^{3} / \mathrm{h}$ desejados, em face do reduzido rendimento de alguns dos poços em determinados setores da área.

Além das implicações causadas por falhas nos sistemas aquíferos porosos, novas captações são usualmente locadas para minimizar a interferência com poços adjacentes (FEITOSA et al., 2008). Nesse contexto, a presente pesquisa adotou uma abordagem alternativa no sentido de otimizar locações adicionais de poços em um aquífero não confinado, compartimentado por falhas, fundamentada na utilização de dados hidrogeofísicos e modelos numéricos. Esse caráter metodológico multidisciplinar objetivou, em última análise, incrementar critérios de locação de poços nesse cenário hidrogeológico, buscandose igualmente identificar áreas mais promissoras, em detrimento de priorizar apenas a redução da interferência entre poços adjacentes, por exemplo.

Figura 1 - Área de estudo localizada na Faixa Costeira Leste do Rio Grande do Norte, Nordeste do Brasil, com destaque para as lagoas do sistema Bonfim e a bateria de poços inserida na margem direita do baixo curso do Riacho Boa Cica

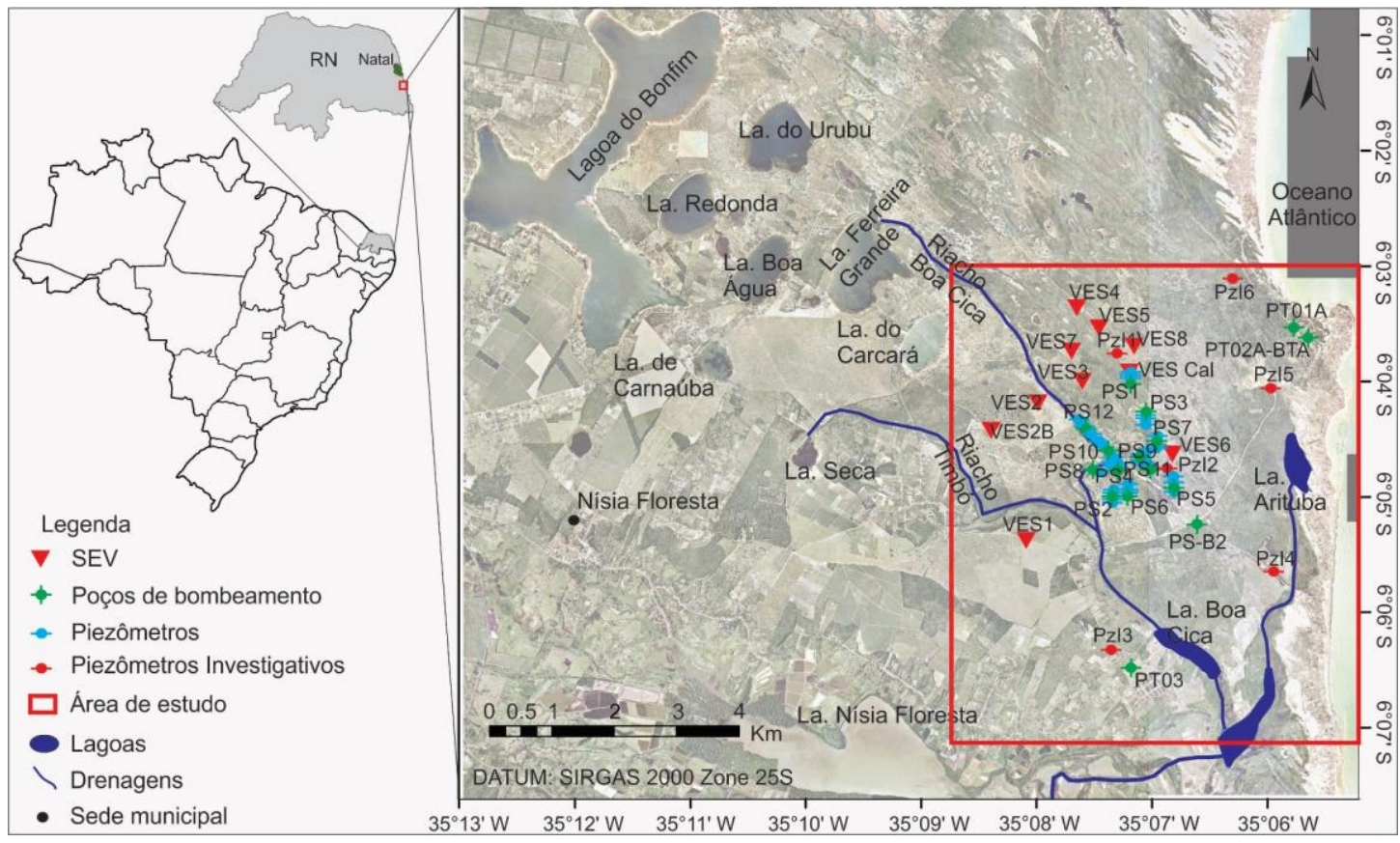

\section{CONTEXTO GEOLÓGICO}

A área de pesquisa está inserida na Bacia Sedimentar Costeira Pernambuco-Paraíba (BALSAMO et al., 2013; BEZERRA et al., 2014), na Faixa Litorânea Leste do Estado do Rio Grande do
Norte, Nordeste do Brasil. A estratigrafia regional é composta por duas sequências básicas: uma não aflorante e outra aflorante. A sequência não aflorante corresponde ao embasamento cristalino e sedimentação Mesozoica. 0 primeiro é constituído de granitos, granodioritos, migmatitos e gnaisses, corre- 
lacionados ao Complexo Caicó, conforme Bezerra (1998) e Lucena (2005). Já a sedimentação Mesozoica, de idade Cretácea, compõe uma unidade basal arenítica e, no topo, uma unidade calcárea com intercalações areníticas, repousando em discordância sobre o embasamento cristalino (LUCENA, 2005).

A sequência aflorante (Figura 2) é representada pela sedimentação Cenozoica, abrangendo desde a Formação Barreiras até os depósitos Quaternários, sendo este último constituído de beachrocks, depósitos praiais sub-recentes e recentes (LUCENA, 2005), depósitos aluviais, diversas gerações de dunas, depósitos de mangues e/ou fluvio-lacustrinos e depósitos arenosos (ROSSETTI et al., 2011).

A Formação Barreiras, particularmente, representa a base da sequência Neógena (LUCENA, 2005; ARAÚJO et al., 2006; NOGUEIRA et al., 2010; ROSSETTI et al., 2013) e é constituída, da base para o topo, por arenitos médios a grossos, por vezes conglomeráticos, e rochas areno-argilosas ou argilo-arenosas. Estas características faciológicas imprimem condições de variação lateral de fácies nas rochas desta unidade sedimentar, tanto vertical, como horizontalmente.

Figura 2 - Mapa geológico regional e unidades estratigráficas aflorantes na área de estudo

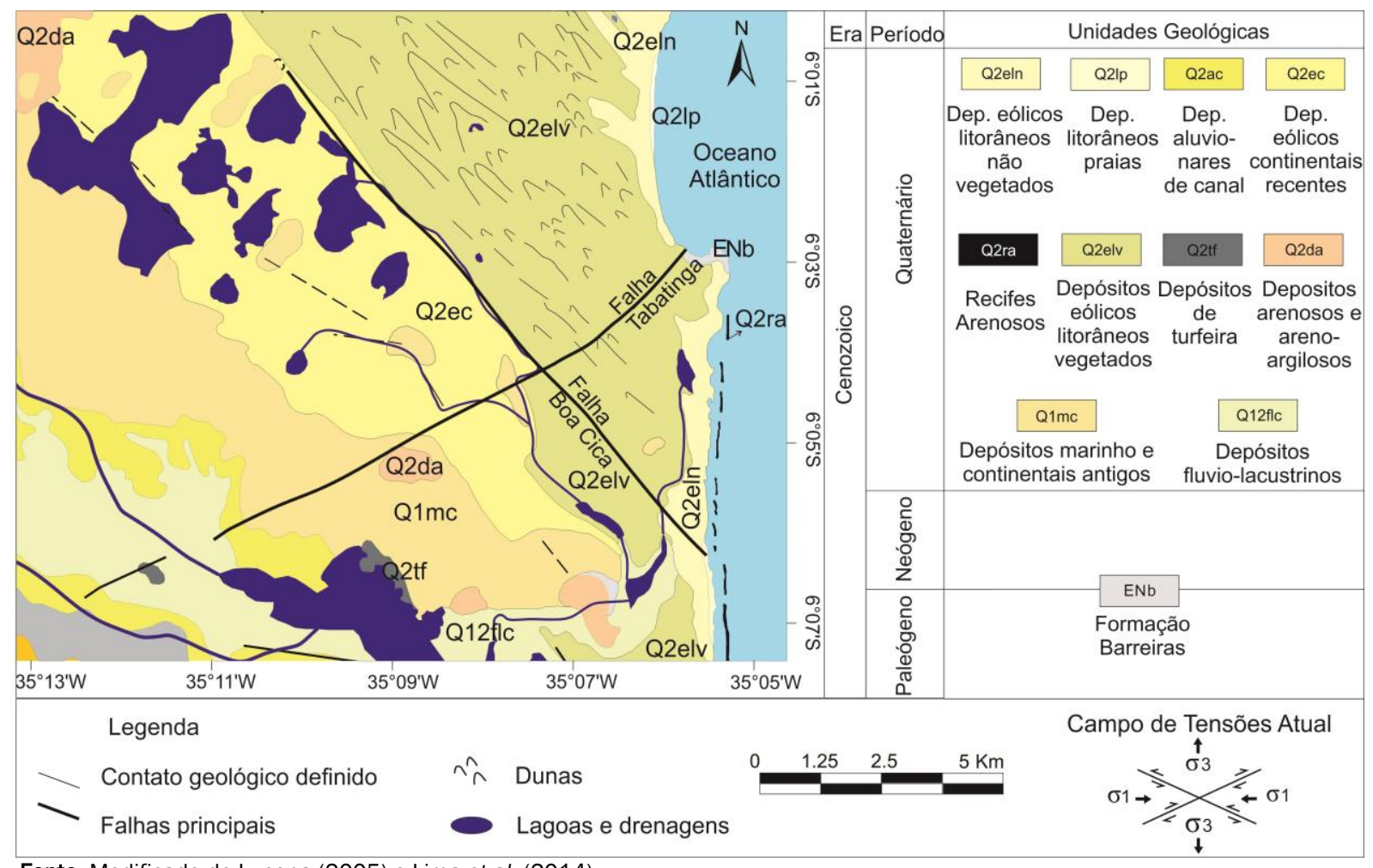

Fonte: Modificado de Lucena (2005) e Lima et al. (2014).

A Bacia Costeira Pernambuco-Paraíba é caracterizada por uma estruturação regional com trends de falhas nas direções preferenciais NE-SW $\left(\mathrm{N} 40^{\circ}-60^{\circ} \mathrm{E}\right)$, NW-SE $\left(\mathrm{N} 40^{\circ}-50^{\circ} \mathrm{W}\right)$, E$\mathrm{W}\left(\mathrm{N} 70^{\circ}-\mathrm{W} / \mathrm{E}-\mathrm{W}\right)$ e, menos expressivamente, N-S $\left(350^{\circ}-10^{\circ}\right)$, sendo aquelas de trends de direção NE e NW dominantes (BEZERRA et al., 2001; NOGUEIRA et al., 2006; BEZERRA et al., 2014; LIMA et al., 2014).

Essas falhas são caracterizadas por movimentos transcorrentes e normais, possivelmente associadas à deformação sinsedimentar (NOGUEIRA et al., 2006). Bezerra et al., (2001) identificaram uma compressão horizontal máxima E-W, com início no Neógeno, que juntamente com uma distensão N-S definem o campo de tensões Neotectônico. Esse campo de tensões favoreceu a configuração de estruturas transcorrentes dextrais (NE-SW) e sinistrais (NW-SE).

Essa estruturação ocasiona a existência de blocos estruturais tipo grabens e horsts, além da presença de falhamentos escalonados, os quais estão vinculados aos falhamentos principais que delimitam tais blocos. Afora essas características, essa estruturação molda a geometria da Formação Barreiras e aquífero homônimo, o controle dos principais vales da região e a acomodação de unidades estratigráficas quaternárias segundo direções preferenciais (LUCENA, 2005). Em blocos abatidos a sedimentação pode ter considerável dimensão, originando zonas saturadas relevantes e de grande capacidade de transmissão hidráulica (BALSAMO et al., 2010; LUCENA et al., 2013).

No contexto específico da área de pesquisa, destaca-se uma proeminente anomalia gravimétrica residual de magnitude -4 mGal, associado ao Graben Papary (LUCENA, 2005), disposto na direção NW e corroborando uma estruturação profunda e que seciona toda a sequência sedimentar reportada. A presença das Falhas Tabatinga (NE) e Boa Cica (NW), esta última representando um nos limites do Graben Papary, detêm forte controle na compartimentação estrutural local (LUCENA, 2005; NOGUEIRA et al., 2006), além de apresentarem marcadores no terreno e datações realizadas em sedimentos praiais sub-recentes e beachroks, respectivamente, evidenciando reativações ativações quaternárias (BEZERRA, 1998; BARRETO 
et al., 2002; LUCENA, 2005).

\subsection{Contexto Hidrogeológico}

O Aquífero Barreiras, tomado como alvo do presente estudo, é considerado o manancial subterrâneo mais importante da Faixa Litorânea Leste do Estado do Rio Grande do Norte. Seu limite inferior é assinalado pelo topo da sequência carbonática Mesozoica não aflorante, enquanto que seu limite superior é, ocasionalmente, representado por sedimentos inconsolidados de dunas, as quais desempenham um importante papel como transmissor de precipitações pluviométricas que infiltram e recarregam o aquífero (MELO et al., 2014). O seu caráter hidráulico predominantemente livre, com semi-confinamentos localizados, deve-se à variabilidade faciológica da Formação homônima, sendo esses semi-confinamentos decorrentes da presença de lentes de argilitos ou siltitos da própria Formação Barreiras (LUCENA, 2005; SOUZA et al., 2019; NUNES et al., 2020).

As transmissividades (T) locais, obtida em testes de aquífero, são da ordem de $10^{-4}$ a $10^{-2} \mathrm{~m}^{2} / \mathrm{s}$, enquanto que as condutividades hidráulicas (K) são da ordem de $10^{-4} \mathrm{~m} / \mathrm{s}$, com descargas individuais de até $100 \mathrm{~m}^{3} / \mathrm{h}$. Autores como Lucena et al., (2013) e Alves et al., (2016) estimaram porosidades eficazes de $10 \%$. Estudos petrográficos e processamento de imagens de lâminas delgadas dessa formação aquífera realizados por Silva et al., (2014), por outro lado, definiram porosidades eficazes de 7,6\%. Já Lucena et al., (2016) obteve porosidades eficazes superiores a $11 \%$ em arenitos similares nas proximidades, embora de idade Mesozoica, igualmente a partir de análise computacional de imagens provenientes de lâminas delgadas. Observações preliminares acerca da potenciometria local evidenciam o fluxo subterrâneo principal em direção ao Oceano Atlântico e, secundariamente, para o Riacho Boa Cica.

\section{METODOLOGIA}

Em linha gerais, a presente pesquisa foi conduzida no sentido de identificar áreas mais promissoras para locação de poços em um cenário hidrogeológico poroso e compartimentado por falhas, a partir de uma abordagem multidisciplinar e alternativa baseada em dados hidrogeofísicos e modelos numéricos. Nesse aspecto, a metodologia foi fundamentada inicialmente buscando-se aprofundar a caracterização hidrogeológica, particularmente sua compartimentação estrutural, através de mapa de espessura saturada e seções hidrogeofísicas. Posteriormente, modelos numéricos foram gerados com vistas a simular respostas do aquífero em termos de locações em distintos blocos estruturais localmente caracterizados.

Considerando a não uniformidade de distribuição de informações diretas de poços ao longo da área de pesquisa, realizouse um levantamento geoelétrico, o qual se destinou a subsidiar a elaboração de seções hidrogeofísicas, com a caracterização de estruturas em subsuperfície, além de incrementar a elaboração de modelos hidrogeológicos conceituais locais mais robustos. A modalidade de investigação foi a da sondagem elétrica vertical (SEV), em face de sua ampla aplicabilidade na pesquisa de águas subterrâneas (ORELLANA, 1972; $\mathrm{KIRSCH}, 2006)$. 0 dispositivo de medições das resistividades aparentes foi o quadripolo linear simétrico AMNB tipo Schlumberger.

O modelo geoelétrico adotado baseia-se nas seguintes premissas (KOEFOED, 1979; LUCENA, 2005): (i) o subsolo é constituído por uma sequência de camadas planas, horizontais e paralelas ao terreno, com espessuras $\left(E_{i}\right)$ finitas, excetuandose a última que é dada como infinita; (ii) admite-se que cada camada é eletricamente homogênea e isotrópica, atribuindose uma resistividade $\left(\rho_{i}\right)$. A última camada, considerada infinita, corresponde, na área, à sequência mesozoica não aflorante.

Um total de nove sondagens elétricas verticais foram executadas, sendo uma de calibração. Esta última foi levantada adjacente a um poço de perfil litológico conhecido, onde as espessuras dos diversos litotipos foram fixados, obtendo-se as respectivas resistividades mediante um melhor ajuste da curva interpretada (modelo inverso) ao dado de campo (nos apêndices é possível visualizar o modelo geoelétrico da SEV de calibração e o respectivo perfil do piezômetro PZ3-PS1). A interpretação qualitativa e quantitativa dessas SEVs foi efetuada com a utilização de software específico de inversão geoelétrica, o IPI2win (BOBACHEV et al., 2000).

Os modelos geoelétricos inversos 1D forneceram a profundidade do topo e da base do aquífero, além de variações litológicas ao longo de todo o perfil vertical. Conforme reportado, os referidos modelos geoelétricos inversos 1D, juntamente com os perfis de poços, foram utilizados na elaboração de seções hidrogeofísicas e obtenção do mapa de espessura saturada, bem como na definição de camadas do modelo hidrogeológico conceitual. 0 mapa de espessura saturada, particularmente, foi obtido a partir de gridagem e interpolação dos dados de poços e modelos geoelétricos, o qual foi posteriormente sobreposto ao mapa estrutural, enfatizando-se a compartimentação do aquífero na área.

A utilização de modelos numéricos objetivou aprofundar o conhecimento acerca do comportamento hidráulico do aquífero, além de simular um incremento da captação existente. A plataforma empregada foi a Visual MODFLOW Pro Classic Interface versão 2015.1. O MODFLOW baseia-se nas equações da Lei da Conservação da Massa e da Lei de Darcy, as quais governam o fluxo subterrâneo (ANDERSON E WOESSNER, 1992), considerando o meio heterogêneo e anisotrópico. Como resultado, tem-se a equação fundamental de fluxo disposta na equação 1:

$\frac{\partial}{\partial x}\left(K_{X} \frac{\partial h}{\partial x}\right)+\frac{\partial}{\partial y}\left(K_{y} \frac{\partial h}{\partial y}\right)+\frac{\partial}{\partial z}\left(K_{z} \frac{\partial h}{\partial z}\right)+R(x, y, z, t)=$ $S_{S}\left(\frac{\partial h}{\partial t}\right)$ 
Onde, Kx, Ky e Kz correspondem à condutividade hidráulica ao longo dos eixos $\mathrm{x}, \mathrm{y}$ e $\mathrm{z}$, respectivamente, em $(\mathrm{L} / \mathrm{T})$; $\mathrm{R}$ é a recarga e/ou extrações $\mathrm{W}$ (fontes e sumidouros do aquífero), em $\left(\mathrm{L}^{3} / \mathrm{TL}^{3}\right)$; h representa a variação de carga hidráulica no espaço tridimensional, em (L); Ss é o coeficiente de armazenamento específico (1/L), sendo o tempo representado por t. A equação fundamental é resolvida através do Método de Diferenças Finitas (OLIVEIRA, 2002).

A área modelada integralizou cerca de $42 \mathrm{~km}^{2}$, incluindo um modelo digital de terreno SRTM (Shuttle Radar Topography Mission), sendo a mesma dividida em 380 linhas e 315 colunas, com resolução de $30 \mathrm{~m}$. A partir da análise dos perfis de poços e SEVs, a discretização vertical foi definida para um modelo de 3 camadas geológicas e 5 camadas matemáticas, proporcionando espessuras semelhantes em todas as camadas, objetivando uma melhor estabilização do processo de convergência do modelo e, consequentemente, sua calibração. A recarga foi calculada pelo método de variação de carga e totalizou 375 mm/ano.

As condições de contorno definidas foram do Tipo I e II (ANDERSON e WOESSNER, 1992). A condição do Tipo I, fluxo conhecido, é caracterizada pelo Riacho Boa Cica (limite oeste e sul, através de atividade de campo) e potenciometria (limite norte, a partir de mapa de fluxo elaborado previamente ao modelo construído). A condição de contorno do Tipo II, carga constante igual a zero, foi inserida no limite do aquífero modelado com o Oceano Atlântico.

A condutividade hidráulica foi interpolada no MODFLOW pelo método IDW (Inverso do Quadrado da Distância). Esses valores representam $\mathrm{K}$ atribuídos aos eixos $\mathrm{x}$ e $\mathrm{y}$, sendo o valor de $\mathrm{K}$ no eixo $\mathrm{z}$ atribuído de $10 \%$ destes últimos (ANDERSON e
WOESSNER, 1992). Ainda de acordo com Anderson e Woessner (1992), a raiz média quadrática (RMS) que caracteriza o modelo como preciso é de até $10 \%$.

Uma vez calibrado o referido modelo, simulações foram conduzidas no sentido de locação de dois poços adicionais de bombeamento, a fim de atingir os $900 \mathrm{~m}^{3} / \mathrm{h}$ pretendidos no início dos estudos. Tais locações, afora o aspecto de gerenciamento hídrico, buscou simular a resposta numérica em termos de locações em grabens e horsts relativos locais, considerando-se o mapa de espessura saturada.

\section{APRESENTAÇÃO E DISCUSSÃO DOS RESULTADOS}

Considerando a calibração geoelétrica previamente executada, intervalos aproximados de resistividades inferiores a $150,150-500$ e superiores a 500 Ohm.m dizem respeito a argilitos, argilitos arenosos a arenitos argilosos e arenitos mais limpos, respectivamente, dentro do contexto da zona saturada. Esses valores mostram-se coerentes com bibliografia sobre métodos resistivos (Telford et al.,, 1990; Dobrin e Savit, 1998; Feitosa et al.,, 2008).

O limite inferior do aquífero, demarcado pelo topo da sequência carbonática Mesozóica, é assinalado por resistividades inferiores a 70 Ohm.m, no caso de argilitos a arenitos calcíferos, embora com tendências a valores mais elevados quando da ocorrência de rochas carbonáticas mais puras (ramo final ascendente da curva no gráfico $A B / 2 \times$ resistividades). A Figura 3 apresenta as SEVs 6 e 8 (como exemplificativas das demais), com os dados de campo, curva ajustada (dado calculado) e modelo geoelétrico inverso (espessuras $\mathrm{x}$ resistividades).

Figura 3 - SEVs 6 (A) e 8 (B), com os respectivos dados de campo (preto), curva ajustada (vermelho) e modelo geoelétrico inverso (espessuras $x$ resistividades). Os valores de erro de ajuste nos modelos inversos situaram-se no intervalo de 5 a $20 \%$

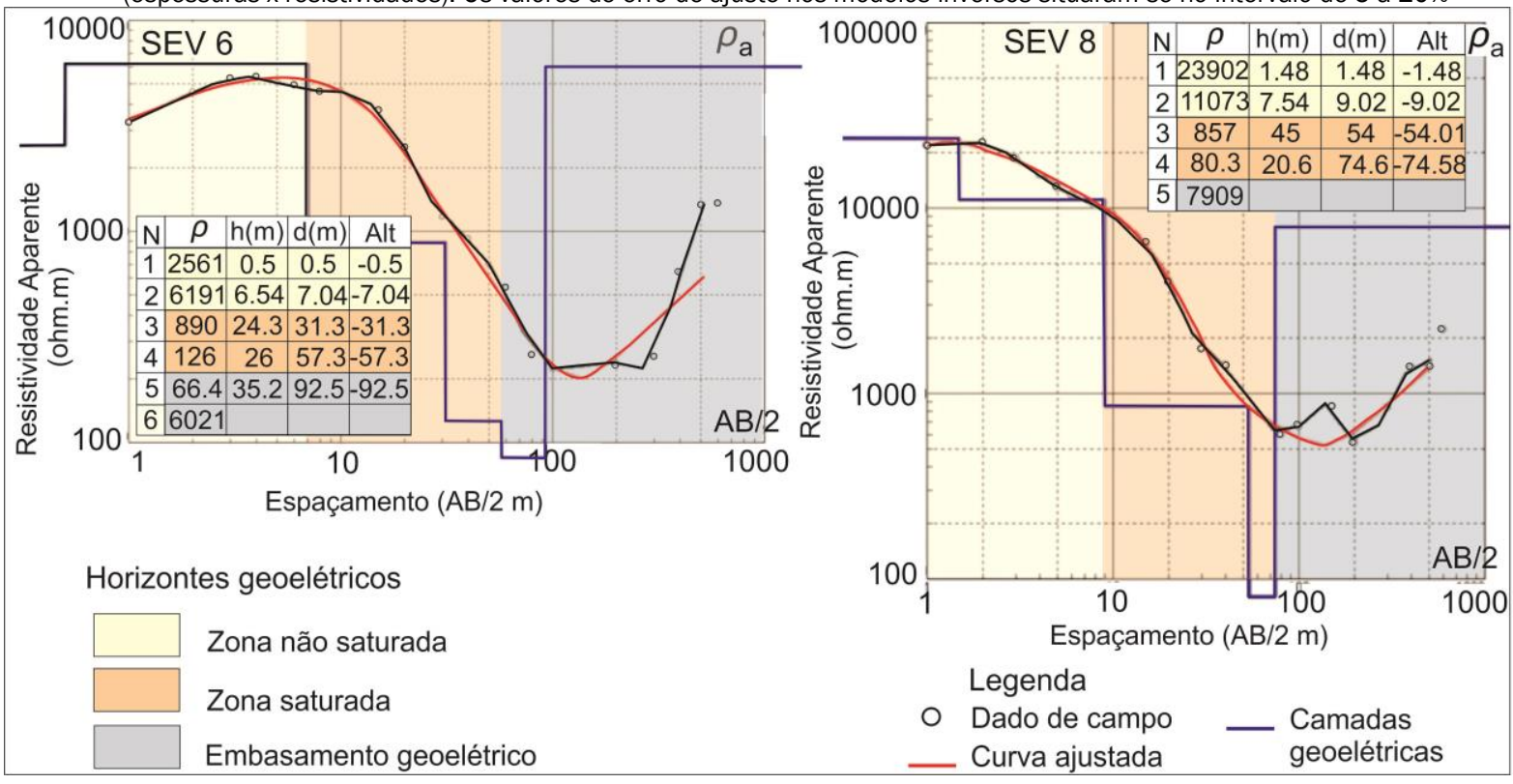


Correlacionando os perfis de poços e os resultados das SEVs, foram elaboradas seções hidrogeofísicas, de modo que as mesmas interceptassem as principais estruturas rúpteis locais, de trends NE e NW (Figura 4).

As seções revelaram o posicionamento médio do nível freático do aquífero, variações litológicas e de espessura saturada. A influência da estruturação regional é demonstrada através da caracterização de grabens e horsts relativos (analogia entre blocos estruturais adjacentes), enfatizando a compartimentação do aquífero.

A Seção Hidrogeofísica A-B (Figura 4), com direção NW-SE, intercepta a Falha Tabatinga e dispõe-se paralelamente ao Riacho Boa Cica. A SEV 05 caracteriza um horst relativo, de ele- vado rejeito, proporcionando uma diminuição local da espessura do aquífero. Os piezômetros PZ03 P01/SEVCAL e PZ01 $\mathrm{P} 03$, assinalam uma profundidade da base do aquífero em aproximadamente $-40 \mathrm{~m}$.

A Seção Hidrogeofísica C-D, de direção SW-NE e interceptando a Falha Boa Cica, delimita um graben relativo local na altura do PZI01, sendo delimitado pelas SEVs 3 e 8. A região central do perfil destaca-se pela ocorrência de falhamentos, onde a base do aquífero atinge cotas de -42 e -37 m. O PZI06, na porção NE, define o principal graben relativo nesta seção, enquanto que as SEVs 2 e $2 \mathrm{~B}$ assinalam um horst relativo. Entre as SEVs 2 e 3, a seção intercepta a Falha Boa Cica que exibe um rejeito de aproximadamente $25 \mathrm{~m}$.

Figura 4 - Mapa de localização e seções hidrogeofísicas A-B e C-D exibindo falhamentos, camadas interpretadas e posição do nível freático

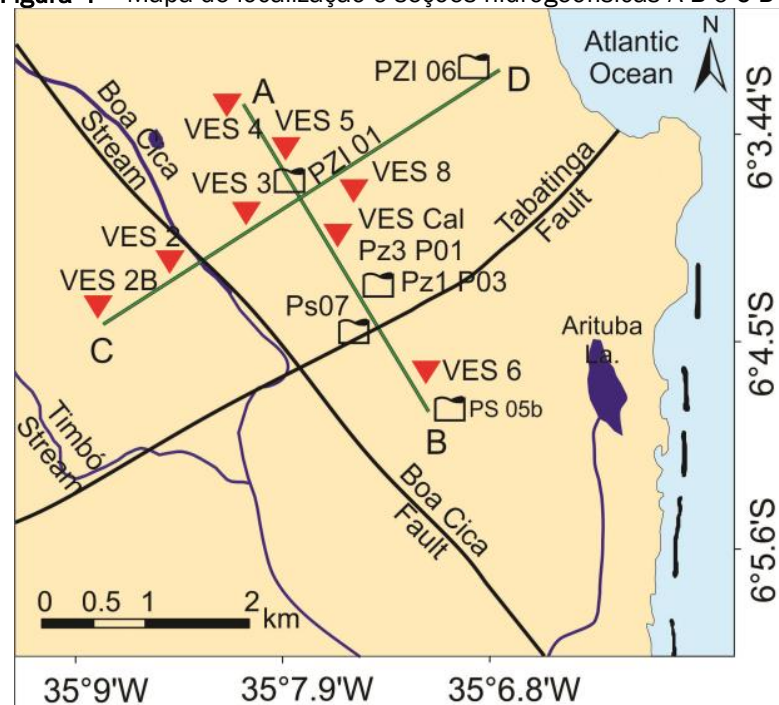

Legend

- Inferred potenciometric surface

Pumping or observation well

$\nabla$ VES

Unconsolidated sediments

Clay sandstone - sand clay

Medium to coarse-grained Sandstone

Calciferous sandstone-Carbonate rocks

- Geological contact

- - Inferred geological contact

- Fault

III Interpreted fault

$\checkmark$ Drainage

$\underbrace{A}_{B}$ Hydrogeophysics cross-section

Hydrogeophysics cross-section A-B
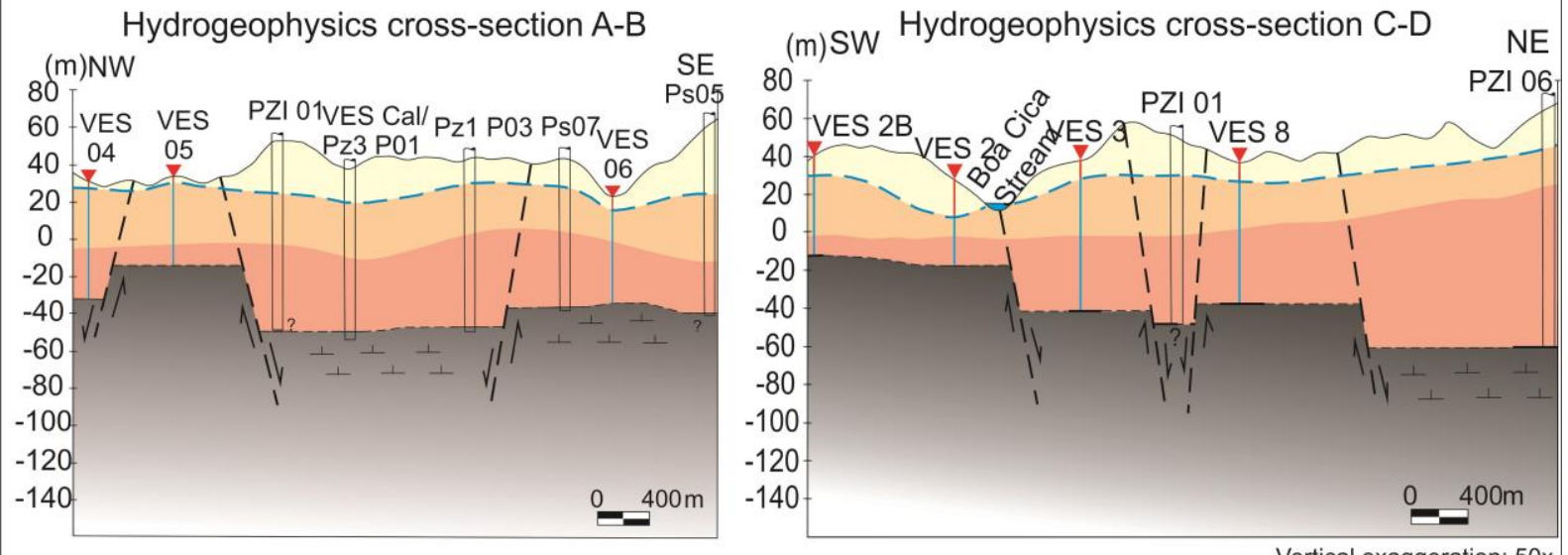

Vertical exaggeration: $50 \mathrm{x}$

Na porção nordeste da área, as falésias expõem a Formação Barreiras representando arenitos bastante fraturados e presença de cimentação de óxido de ferro (Figura 5A). Nas falésias predominam conjuntos de fraturas com direção NE, subverticais, com critérios cinemáticos fundamentados em estrias de falha.

Dentre os marcadores de terreno associado com o campo de tensões Neógeno, tem-se no limite norte da falésia na locali- dade de Barra de Tabatinga a interrupção brusca do registro de sedimentos praiais sub-recentes datados de 210.000 anos (BARRETO et al., 2002), associado à Unidade Barra de Tabatinga (LUCENA, 2005), além de seu basculamento no sentido norte, compatível com uma distensão N-S (б3) (Figura 5B). Feições outras em beachrocks imediatamente a sul dessa localidade e com datações associadas dão conta de reativações em aproximadamente 6000 A.P (BEZERRA, 1998). 
Figura 5 - Afloramento da Formação Barreiras na praia de Tabatinga, caracterizada na forma de falésia decorrente do deslocamento dessa formação na linha de costa $(A)$ e sua disposição em relação às unidades estratigráficas sobrepostas (B)
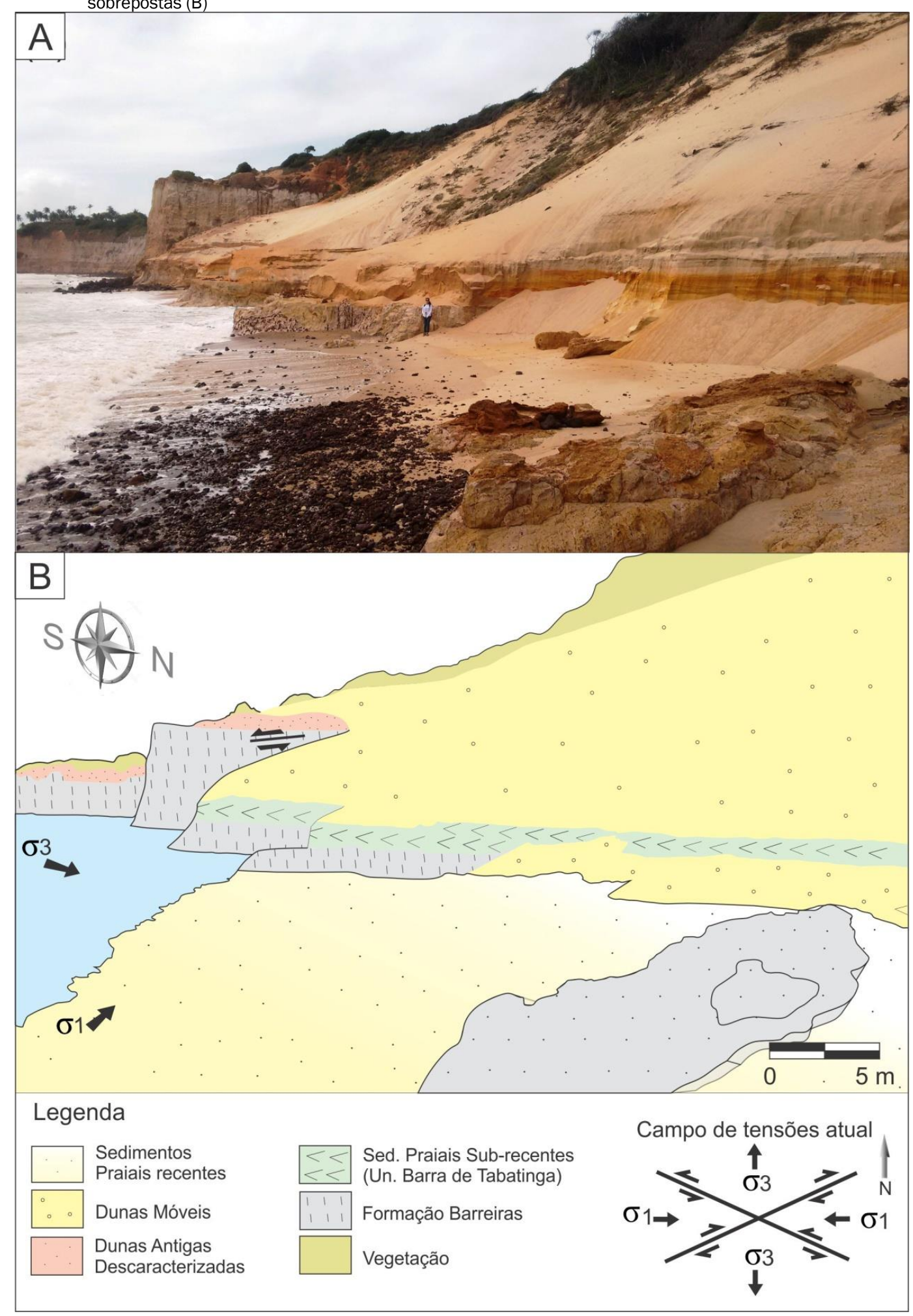

O mapa de espessura saturada local (Figura 6A) evidencia isolinhas de 30 a 40 m na margem direita do Riacho Boa Cica, enquanto que porção nordeste verifica-se isolinhas de até 90 $\mathrm{m}$ nas proximidades da falésia de Tabatinga. Essa configuração decorre do abatimento do substrato carbonático causado pelas falhas, destacando-se a área sob influência do Graben Papary a nordeste do mapa, limitado, aproximadamente, pela isolinha de $50 \mathrm{~m}$ (região central do mapa de espessura saturada). A Figura 6B revela um perfil característico de poço nesse contexto, ressaltando-se a predominância de rochas de maior granulometria na base do aquífero. Uma síntese da geologia da área de estudo e adjacências é apresentada na Figura 7, com ênfase na estruturação regional. 
Figura 6 - Mapa de espessura saturada do Aquífero Barreiras na margem direita do Riacho Boa Cica, elaborado a partir de dados de poços e modelos inversos de SEVs (A); perfil litológico-construtivo do poço tubular PS4, ressaltando-se sua variação litológica característica (B)

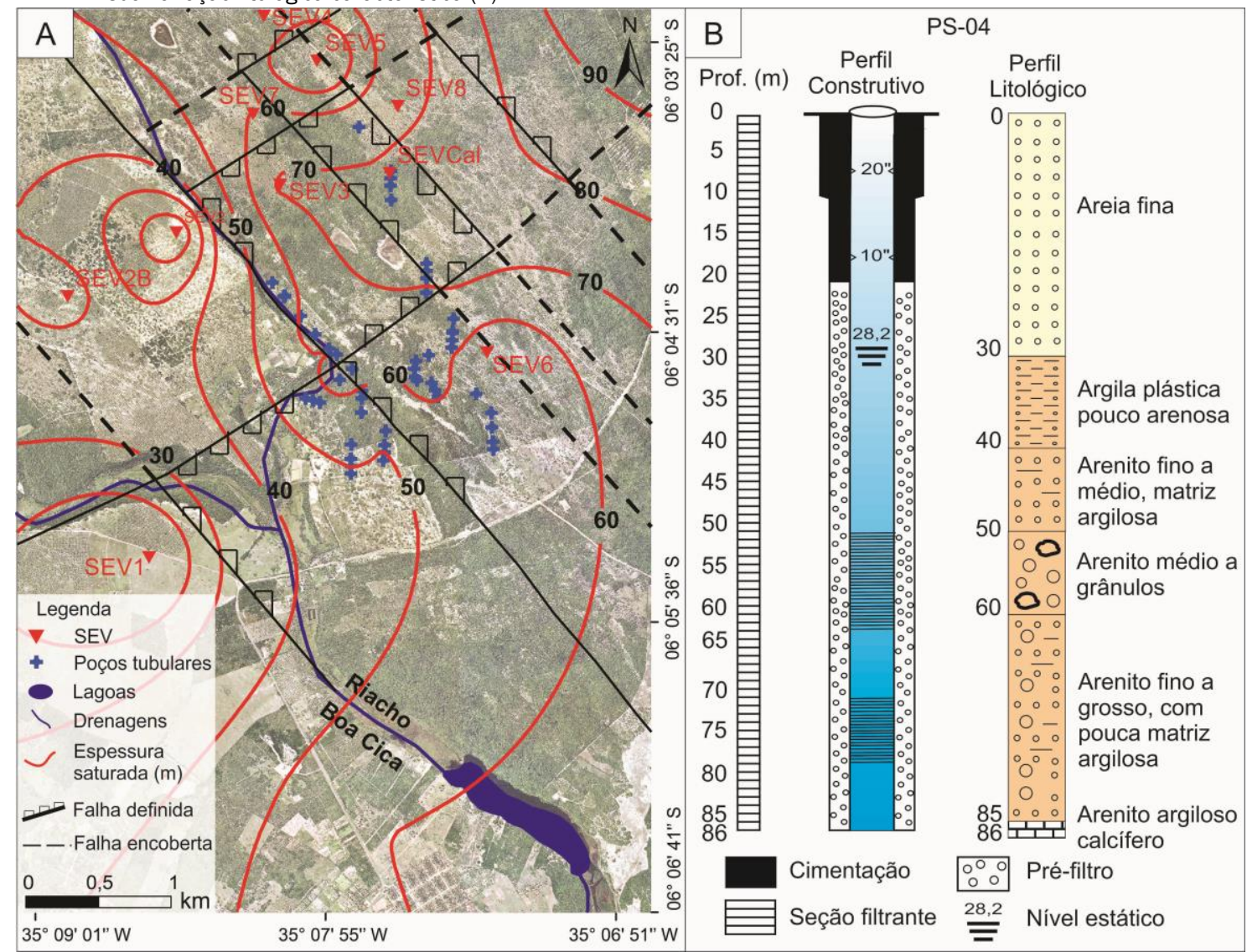

Figura 7 - Síntese da geologia da área de estudo com destaque para as Falhas Riacho Boa Cica (NW) e Tabatinga (NE); notar a disposição de falhamentos secundários associados dentro do Graben Papary, na região NE da área de estudo

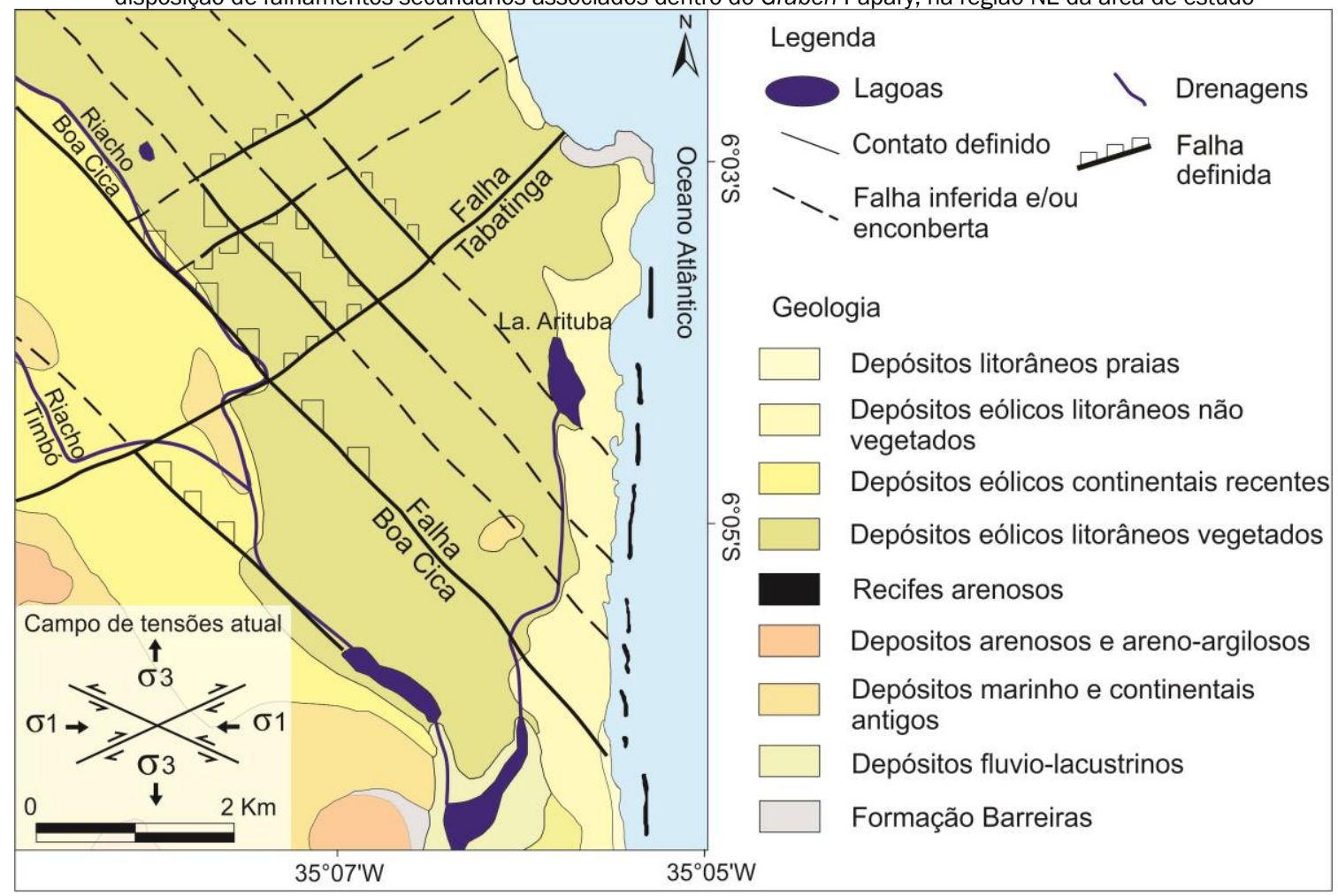

Fonte: Modificado de Lucena (2005) e Lima et al. (2014). 
O modelo conceitual adotado para o Aquífero Barreiras na área foi definido na forma de três camadas geológicas, conforme reportado, apresentando-se da seguinte forma (Figura 8): Camada 1 - coberturas arenosas representadas por areia fina a muito fina, bem selecionada; Camada 2 - arenito fino a médio e ocorrência de matriz argilosa, com intercalações de argila plástica; Camada 3 - arenito fino a muito grosso, com níveis conglomeráticos, pouca ou nenhuma argila.
Os valores de condutividade hidráulica calculados foram averiguados quanto a sua coerência com os perfis litológicos, interpolados e inseridos nas respectivas camadas. 0 valor médio encontrado para cada camada foi de: $1,24 \mathrm{e}^{-4} \mathrm{~m} / \mathrm{s}, 3,66 \mathrm{e}$ $5 \mathrm{~m} / \mathrm{s}, 5,51 \mathrm{e}^{-4} \mathrm{~m} / \mathrm{s}$, respectivamente para as camadas $1,2 \mathrm{e}$ 3. 0 modelo digital de elevação revela um terreno com predominância de dunas registrando cotas topográficas de até 95 m no corredor que margeia o Riacho Boa Cica (ver Figura 8).

Figura 8 - Modelo conceitual definido para o Aquífero Barreiras na área de estudo e seus respectivos valores de condutividade hidráulica média para cada camada geológica

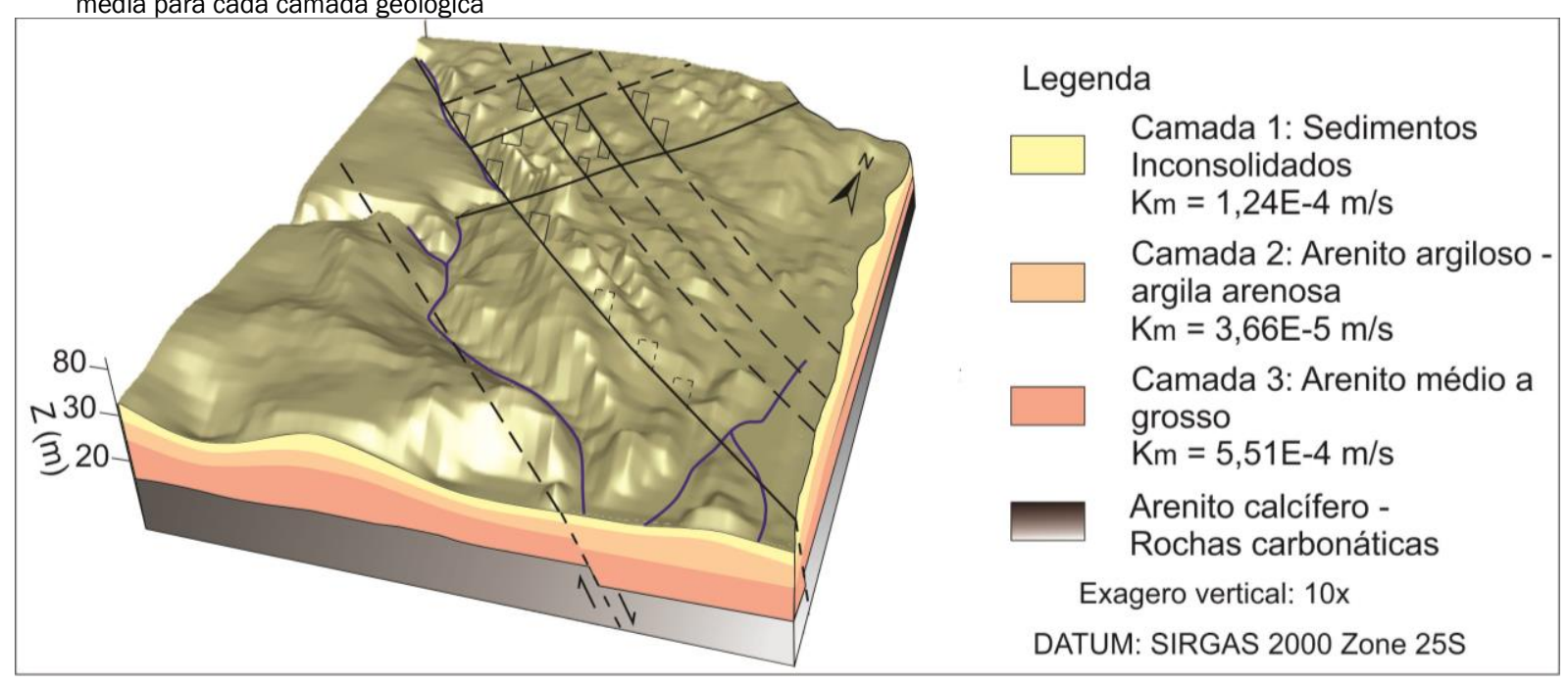

O modelo numérico, por sua vez, além da concepção do modelo conceitual, incorporou a compartimentação estrutural do aquífero na forma de variações de espessuras das camadas 2 e 3, além das variações do topo da sequência carbonática mesozoica (base do aquífero). O modelo numérico foi concebido em regime permanente, pois as medições de carga hidráulica (condição inicial) foram feitas anteriormente ao início do bombeamento da bateria de poços.

A calibração foi efetuada através de modelagem direta mediante ajustes nos valores de recarga e condutividade hidráulica. A primeira foi calibrada em $330 \mathrm{~mm} / \mathrm{ano}$, enquanto que os valores médios de $\mathrm{K}$ em cada camada foi de: $1,08 \mathrm{e}^{-4} \mathrm{~m} / \mathrm{s}$, $2,94 \mathrm{e}^{-5} \mathrm{~m} / \mathrm{s}, 1,26 \mathrm{e}^{-4} \mathrm{~m} / \mathrm{s}$, respectivamente para as camadas 1,2 e 3.

A Raiz Média Quadrática (RMS) do modelo calibrado foi de
8,9\% e a discrepância entre entradas e saídas da ordem de 0,08\% (Figura 9A e 9B). A Figura 9C representa o mapa de vetor de velocidade na camada 3 , cuja tendência geral do fluxo subterrâneo é no sentido do Oceano Atlântico, embora se tenha fluxos secundários no sentido do Riacho Boa Cica.

Considerando o modelo numérico calibrado, simulações foram efetuadas no sentido de aumentar a capacidade instalada na captação em questão, na forma de dois poços adicionais. Os poços simulados possuem profundidade de aproximadamente $70 \mathrm{~m}$, com os filtros posicionados na camada $3 \mathrm{e}$ espessura de $20 \mathrm{~m}$. Estes foram locados em cenários de distintos valores de espessura saturada (graben e horst relativos), guiados pelas seções hidrogeofísicas e o próprio mapa de espessura saturada, analisando-se as respectivas respostas em termos de ajustes entre cargas hidráulicas observadas e calculadas, dentre outros aspectos. 
Figura 9 - Gráfico carga observada x carga calculada para o modelo numérico calibrado (A); balanço de massas resultante (B);

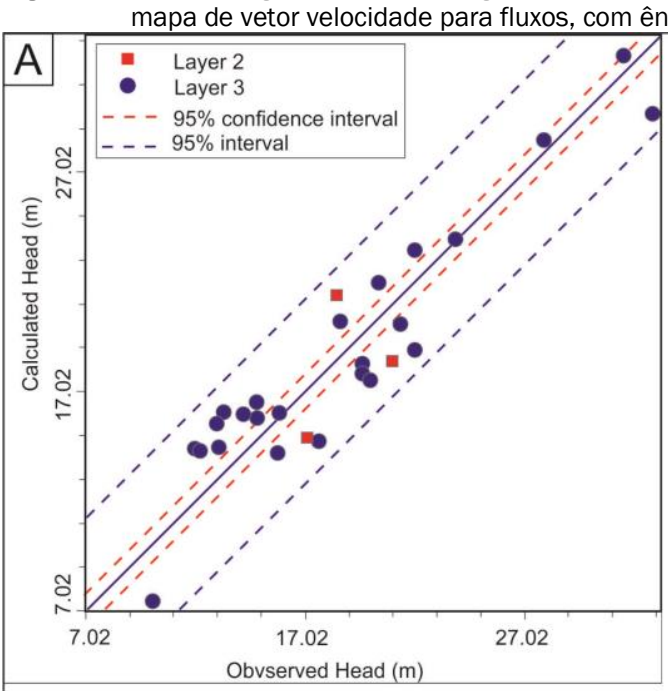
ase na camada 3 do modelo conceitual (C)

\begin{tabular}{|l|c|c|}
\hline B & \multicolumn{3}{|c|}{ Mass Balance } \\
\hline & IN $\left(10 \mathrm{e}^{6} \mathrm{~m}^{3}\right)$ & OUT $\left(10 \mathrm{e}^{6} \mathrm{~m}^{3}\right)$ \\
\hline Constant head & 0 & 0,025 \\
\hline River & 0,003 & 0,01 \\
\hline Wells & 0 & 0,001 \\
\hline Evapotransp. & 0 & 0,0036 \\
\hline Recharge & 0,038 & 0 \\
\hline Total & 0,041 & 0,04 \\
\hline Discrepance & \multicolumn{2}{|c|}{$0,08 \%$} \\
\hline \multicolumn{3}{|c|}{} \\
\hline
\end{tabular}

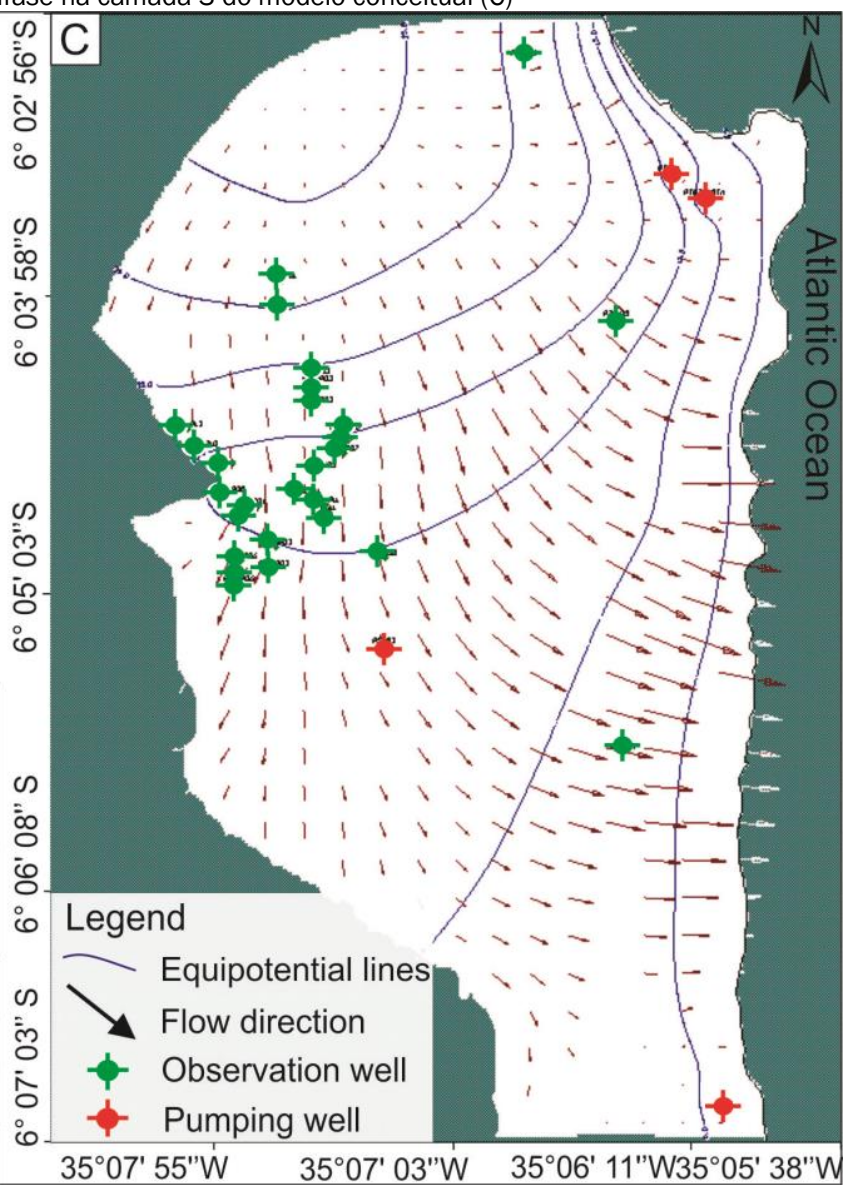

Na simulação 1, selecionou-se uma área de menor espessura saturada (horst relativo) para locação dos dois poços tubulares, com vazão de explotação igual a $75 \mathrm{~m}^{3} / \mathrm{h}$ cada poço, totalizando $150 \mathrm{~m}^{3} / \mathrm{h}$ (Figura 10A). 0 poço S1P01 foi locado na região a sul da captação Boa Cica, onde a espessura saturada é menor em relação a outros setores da área de estudo, entre as isolinhas de 40 e $50 \mathrm{~m}$. 0 poço S1P02 foi locado a $500 \mathrm{~m}$ do primeiro, em região de espessura saturada igualmente reduzida. Nesse caso, o RMS e a discrepância entre entradas e saídas aumentaram, $11,3 \%$ e $0,1 \%$, respectivamente.

Na simulação 2, os poços foram posicionados em um cenário de maior espessura saturada (graben relativo), igualmente com vazões de explotação de $75 \mathrm{~m}^{3} / \mathrm{h}$ (Figura 10B). 0 poço S2P01 foi locado na porção leste da área de estudo e o poço $\mathrm{S} 2 \mathrm{P0} 2$ foi locado a $500 \mathrm{~m}$ do primeiro, onde as isolinhas de espessura saturada apresentam valores superiores a $80 \mathrm{~m}$. Os resultados mostram o RMS inferior a 10\% e a discrepância da ordem de $0,03 \%$.

O cenário mais promissor apresentado na simulação 2 é corroborado com rebaixamentos disponíveis maiores nas subáreas de mini-grabens relativos e, consequentemente, maiores vazões teóricas de explotação. 
Figura 10 - Configuração da simulação 1, onde os poços foram locados no setor oeste da área, em subárea com menor espessura saturada (A); e a disposição da simulação 2, onde os poços foram locados em subárea com maior espessura saturada (B);
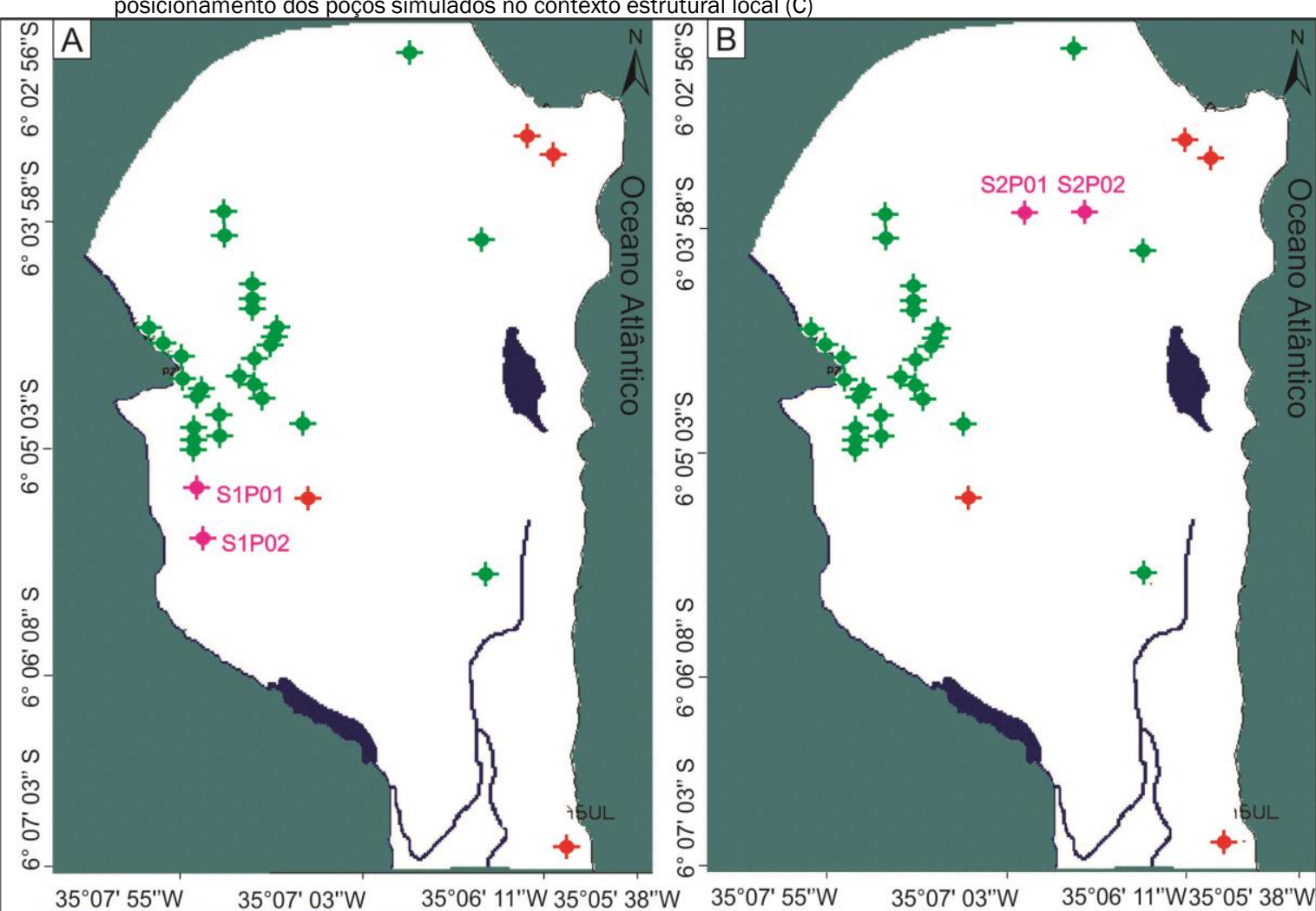

$35^{\circ} 07^{\prime} 55^{\prime \prime} \mathrm{W}$

$35^{\circ} 07^{\prime} 03^{\prime \prime} \mathrm{W}$

$35^{\circ} 06^{\prime} 11$ 'W3505' 38"W

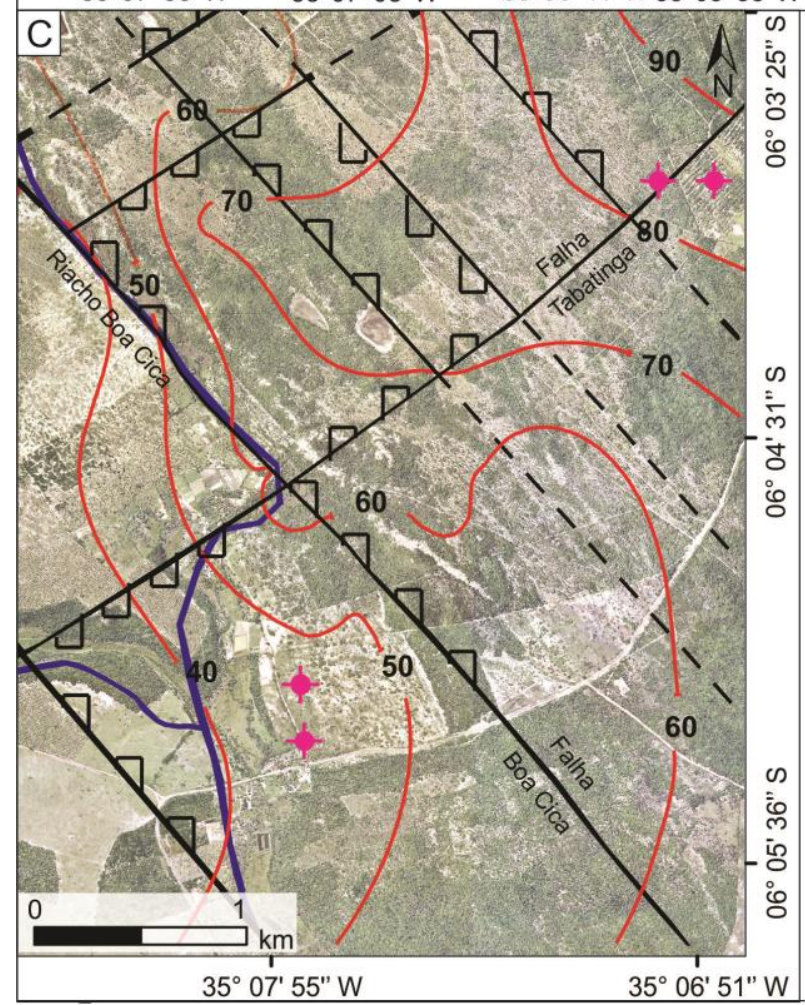

Legenda

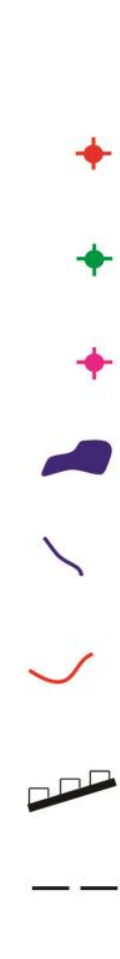

Poços de bombeamento

Piezômetros

- Poços simulados

\section{Lagoas}

\section{Drenagens}

Espessura saturada $(m)$

\section{Falha definida}

\section{Falha encoberta}

\section{CONCLUSÕES}

A adoção da metodologia alternativa ora reportada, particularmente envolvendo levantamentos hidrogeofísicos somado com modelos numéricos, mostrou-se promissora na otimização de locações de poços em aquíferos não confinados poro- sos e sob condicionamento estrutural. Nesse ínterim, obtevese, em última análise, a caracterização de zonas associadas com maiores transmissividades hidráulicas, sinalizadas por maiores espessuras saturadas, considerando-se igualmente a minimização da interferência entre poços. 
No presente estudo, conduzido no sentido de subsidiar o incremento da disponibilidade instalada de uma bateria de poços no Aquífero Barreiras-RN, as variações de espessura saturada ao longo da área decorrem da compartimentação estrutural regional, a qual foi detalhada a partir de correlação em perfis de poços, modelos inversos geoelétricos 1D e averiguações de campo. Nesse aspecto, tem-se a ampla predominância dos trends NW e NE, representados pelas falhas principais Boa Cica e Tabatinga, respectivamente, além daquelas secundárias associadas. Essa contextualização é realçada, dentre outros aspectos, na forma da configuração de mini-grabens e mini-horsts relativos, respectivamente associados com aumentos e diminuições de espessuras saturadas locais.

Os modelos geoelétricos, de 5 a 6 camadas, revelam camadas superiores não saturadas com resistividade de 1623 a 69274 ohm.m. As camadas intermediárias são coerentes com as rochas saturadas da Formação Barreiras e revelam valores de 126 a 915 ohm.m. Já as camadas inferiores, com valores abaixo de 70 ohm.m correspondem aos argilitos a arenitos calcíferos.

A espessura saturada varia de $30 \mathrm{~m}$, na porção SW, na margem direita do Riacho Boa Cica, a 90 m, na porção NE da área. As análises dos perfis litológicos e dos modelos geoelétricos proporcionaram individualizar o aquífero alvo deste estudo em três camadas geológicas. Sendo a primeira composta de coberturas arenosas, a segunda correspondente a uma camada com maior teor de argila e a terceira com arenito fino a grosso e niveis conglomeráticos.

Essa compartimentação estrutural do aquífero foi incorporada a um modelo conceitual e numérico do mesmo, sendo este último calibrado mediante ajustes nas condutividades hidráulicas e com uma taxa de recarga de $330 \mathrm{~mm}$ /ano.

As simulações efetuadas no sentido de analisar respostas do aquífero em termos de modelos de fluxo e cargas hidráulicas (observadas e calculadas), priorizando-se espessuras saturadas e não apenas minimizando-se interferências entre poços, consideraram o posicionamento de novas captações em minigrabens e em mini-horsts. Nesse caso, aquele cenário simulado com o posicionamento dos poços em subárea de minigrabens evidenciou um melhor ajuste em termos de RMS (mantendo-se inferior a 10\%) e discrepâncias entre entradas e saídas da ordem de 0,03\%, em detrimento das locações em subáreas de mini-horsts, considerando as mesmas taxas de descargas $\left(150 \mathrm{~m}^{3} / \mathrm{h}\right)$.

Os resultados apresentados corroboram que os falhamentos exercem influência expressiva no contexto do Aquífero Barreiras, com grabens relativos locais mostrando-se mais promissores para locação de poços uma vez que, normalmente, acham-se associados com maiores rebaixamentos disponíveis e possibilidade de maiores vazões de explotação.

\section{AGRADECIMENTOS}

Os autores agradecem a CAPES (Coordenação de Aperfeiçoa- mento de Pessoal de Nível Superior - Gov. Brasil) pela concessão de bolsa de pesquisa, além da SEMARH (Secretaria do Meio Ambiente e Recursos Hídricos - Gov. RN, Brasil), CAERN (Companhia de Águas e Esgotos do Rio Grande do Norte Gov. RN, Brasil) e Estação Climatológica da Universidade Federal do Rio Grande do Norte, pelo acesso aos perfis de poços, testes de aquífero e dados climatológicos, respectivamente.

\section{REFERÊNCIAS}

ALVES, R. S.; MELO, J. G.; SILVA, C. T. X. L.; OLIVEIRA, C. C. C.; Recursos Hídricos Subterrâneos da Região de Parnamirim, RN: uso das águas e potencialidades. Revista Águas Subterrâneas, v. 30, p. 37-52, 2016. https://doi.org/10.14295/ ras.v30i1.28486

ANA - AGÊNCIA NACIONAL DAS ÁGUAS. Ministério do Meio Ambiente. Estudos Hidrogeológicos para a orientação do Manejo das Águas Subterrâneas da Região Metropolitana de Natal. V. 2 - Avaliação da Urbanização e de outras Atividades Antrópicas nas Águas Subterrâneas, 2012.

ANDERSON, M. P.; WOESSNER, W. W. Applied groundwater modeling: simulation of flow and advective transport. Academic Press Inc.,1992.

ARAÚJO, V.; REYES-PERES, Y.; LIMA, R.; PELOSI, A.; MENEZES, L.; CÓRDOBA, V.; LIMA-FILHO, F. Fácies e sistema deposicional da formação barreiras na região da Barreira do Inferno, Litoral Oriental do Rio Grande do Norte, Geologia USP-Série Cientifica, v. 6 , n. 2, p. 43-49, 2006. https://doi.org/10.5327/ $\underline{\mathrm{S} 1519-874 \times 2006000300006}$

BALL, L. B.; GE, S.; CAINE, J. S.; REVIL, A.; JARDANI, A. Constraining fault-zone hydrogeology through integrated hydrological and geoelectrical analysis. Hydrogeology J. v. 18, p. 1057 1067, 2010. https://doi.org/10.1007/s10040-010-0587-z

BALSAMO, F.; STORTI, F. Grain size and permeability evolution of soft-sediment extensional sub-seismic and seismic fault zones in high-porosity sediments from theCrotone basin, southern Apennines, Italy, Mar. Pet. Geol. v. 27, p. 822-837, 2010. https://doi.org/10.1016/i.marpetgeo.2009.10.016

BALSAMO, F.; STORTI, F.; SALVINI, F.; SILVA, A. T.; LIMA, C. Structural and petrophysical evolution of extensional fault zones in poorly lithified low-porosity sandstones of the Barreiras Formation, NE Brazil. Journal of Structural Geology, v. 32, p. 1806-1826, 2010. https://doi.org/10.1016/ j.jsg.2009.10.010

BALSAMO, F.; BEZERRA, F. H. R.; VIEIRA, M. M.; STORTI, F. Structural control on the formation of iron-oxide concretions and Liesegang bands in faulted, poorly lithified Cenozoic sandstones of the Paraíba Basin, Brazil. GSA Bulletin, v. 125, n. 56, p. 913 931, 2013. https://doi.org/10.1130/B30686.1

BARRETO, A. M. F.; BEZERRA, F. H. R.; SUGUIO, K; TATUME, S. H.; YEE, M.; PAIVA, R. P.; MUNITA, C. S. Late pleistocene marine terrace deposits in northeastern Brazil: sea-level change and tectonic implications, Palaeo, v. 179, p. 57-69, 2002. https://doi.org/10.1016/S0031-0182(01)00408-4 
BENSE, V. F.; PERSON, M. Faults as conduit-barrier systems to fluid flow in siliciclastic sedimentary aquifers. Water Resources, v. 42, W0542, 2006. https://doi.org/10.1029/ 2005WR004480

BEZERRA, F. H. R. Neotectonics in Northeastern Brazil. PhD Thesis, University of London, Inglaterra, 1998

BEZERRA, F. H. R.; AMARO, V. E.; VITA-FINZI, C.; SAADI, A. Pliocene-quaternary fault control of sedimentation and coastal plain morphology in NE Brazil. Journal of South American Earth Sciences, v. 14, p. 61-75, 2001. https://doi.org/10.1016/ $\underline{\text { S0895-9811(01)00009-8 }}$

BEZERRA, F. H. R.; ROSSETTI, D. F.; OLIVEIRA, R. G.; MEDEIROS, W. E.; BRITO NEVES, B. B.; BALSAMO, F., NOGUEIRA, F. C. C.; DANTAS, E. L.; ANDRADES FILHO, C.; GÓES, A. M. Neotectonic reactivation of shear zones and implications for faulting style and geometry in the continental margin of NE Brazil. Tectonophysics, v. 14, p. 78-90, 2014. https://doi.org/10.1016/ j.tecto.2013.12.021

BOBACHEV, A. A.; MODIN, I. N.; SHEVNIN, V. A. IPI2Win v. 2.1, IPI_RES2, IPI_RES3, User's Guide. Geoscan-M Ltd., Moscou, Rússia. 25p, 2000.

DOBRIN M. B.; SAVIT, C. H. Introduction to Geophysical Prospecting. 4th Edition, McGraw Hill, New York, 1998

FEITOSA, F. A. C.; MANOEL FILHO, J.; FEITOSA, E. C.; DEMETRIO, J. G. A. Hidrogeologia: conceitos e aplicações. 3 ed. rev. e ampl. - Rio de Janeiro, CPRM: LABHID, 812 p, 2008.

FERNANDES, A. J.; RUDOLPH, D. L. The influence of Cenozoic tectonics on the groundwater-production capacity of fractured zones: a case study in Sao Paulo, Brazil. Hydrogeology J. v. 9, p. 151-167, 2001. https://doi.org/10.1007/ $\underline{\mathrm{s} 100400000103}$

JOURDE, H.; FLODIN, E. A.; AYDIN, A.; DURLOFSKY, L. J.; WEN,X. $\mathrm{H}$. Computing permeability of fault zones in eolian sandstone from outcrop measurements. AAPG Bulletin, v. 86, p. 11871200, 2002. https://doi.org/10.1306/61EEDC4C-173E11D7-8645000102C1865D

KIRSCH, R. Groundwater Geophysics, a tool for hydrogeology. Berlin: Springer, 2006. 493 p, 2006. https://doi.org/ 10.1007/3-540-29387-6

KOEFOED, O. Geosounding Principles. V. 1: Resistivity Sounding Measurements. Elsevier Science. 290 p. 1979.

LIMA, M. G.; DANTAS, E. P.; MEDEIROS, V. C. Programa Geologia do Brasil-PGB. São José de Mipibu. Folhas SB.25-Y-A-II e SB.25-Y-A-III. Estados do Rio Grande do Norte e Paraíba. Carta Geológica. Recife: CPRM, 1 mapa colorido, 100,0 x 71,0 cm. Escala 1:100.000. 2014. Disponivel em: http://geosgb.cprm.gov.br/downloads/.

LUCENA, L. R. F. Implicação da compartimentação estrutural no Aquífero Barreiras na área da bacia do Rio Pirangi-RN. Tese (Doutorado), Universidade Federal do Paraná, Brasil, 2005

LUCENA, L. R. F.; DA SILVA, L. R. D.; VIEIRA, M. M.; CARVALHO, B. M.; XAVIER JÚNIOR, M. M. Estimating hydraulic parameters of Açu-Brazil aquifer using the computer analysis of micrographs. Journal of Hydrology, v. 535, p. 61-70, 2016. https://doi.org/10.1016/i.jhydrol.2016.01.025

LUCENA, L. R. F.; MEDEIROS, W. E.; OLIVEIRA JR, J. G.; QUEIROZ, M. A. The potential of the Barreiras Aquifer in the lower course of the Doce River, Rio Grande do Norte State, Northeast Brazil - Integration of hydrogeological and geophysical data. Brazilian Journal Geophysics. V. 31, n. 1, p. 43-57, 2013. https://doi.org/10.22564/rbgf.v31i1.245

MELO, J. G.; ALVES, R. S.; SILVA, J. G. Estimativa da recarga das águas subterrâneas do Sistema Aquífero Barreiras na bacia do Rio Pirangi, RN. Revista Águas Subterrâneas, v. 2, n. 28 , p. 68-81, 2014. https://doi.org/10.14295/ ras.v28i2.27428

NOGUEIRA, F. C. C.; BEZERRA, F. H. R.; CASTRO, D. L. Deformação rúptil em depósitos da formação Barreiras na porção leste da Bacia Potiguar. Geologia USP-Série Científica, v. 6, n. 2, p. 51-59, $2006 . \quad$ https://doi.org/10.5327/S1519$\underline{874 \times 2006000300007}$

NOGUEIRA, F. C. C.; BEZERRA, F. H. R.; FUCK, R. A. Quaternary fault kinematics and chronology in intraplate northeastern Brazil. J. Geodyn. v. 49, p. 79-91, 2010. https://doi.org/ 10.1016/i.jog.2009.11.002

NUNES, L. M. G.; LUCENA, L. R. F.; NASCIMENTO SILVA, C. C. Reserve evaluation of a fault-conditioned aquifer: the Barreiras Aquifer in the coastal region of NE Brazil. Brazilian Journal of Geology, v. 50, n. 1, e20180127, 2020. https://doi.org/10.1590/2317-4889202020180127

OLIVEIRA, J. N. Ferramenta de gestão de águas subterrâneas para a cidade de São José do Rio Preto, SP. Thesis (PHD) Universidade de São Paulo, Brasil, 2002.

ORELLANA, E. Prospecion geoeletrica en corriente continua. Ed. Paraninfo, Madrid. 523 p, 1972

ROSSETTI, D. F.; BEZERRA, F. H. R.; DOMINGUEZ, J. M. L. Late Oligocene - Miocene transgressions along the equatorial and eastern margins of Brazil. Earth-Science Reviews, v. 123, p. 87-112, 2013. https://doi.org/10.1016/i.earscirev.2013.04.005

ROSSETTI, D. F.; BEZERRA, F. H. R.; GÓES, A. M.; BRITO NEVES, B. B. Sediment deformation in Miocene and post-Miocene strata, Northeastern Brazil: Evidence for paleoseismicity in a passive margin. Sedimentary Geology, v. 235 , n. 3-4, p. 172 187, 2011. https://doi.org/10.1016/j.sedgeo.2010.02.005

SEMARH - SECRETARIA DE MEIO AMBIENTE E RECURSOS HÍDRICOS. Estudo Hidrodinâmico com Modelagem Numérica para Definição das Condições de Explotação. Projeto Executivo das Subadutoras para Suprimento do Reservatório de Reunião dos Poços da Área Boa Cica para Reforço do Suprimento da Adutora Monsenhor Expedito. TECHNE Engenheiros Consultores Ltda./SEMARH, 2012.

SERHID - SECRETARIA DO ESTADO DE RECURSOS HÍDRICOS. Caracterização Hidrogeológicados Aquífero. Plano Estadual De Recursos Hídricos Relatório HE-1358-R11-0798, Hidroservice/SERHID, 1998. 
SILVA, L. R. D.; LUCENA, L. R. F.; VIEIRA, M. M.; NASCIMENTO A. F. Estimativa de parâmetros hidráulicos do Aquífero Barreiras-RN a partir de análise computacional de imagens de lâminas delgadas. Águas Subterrâneas, v. 28, n. 2, p. 14-27, 2014. https://doi.org/10.14295/ras.v28i2.27873

SOUZA, I. V. F.; LUCENA, L. R. F.; BEZERRA, F. H. R.; DINIZFILHO, J. B. Use of hydrogeophysical data to determine the role of faults in the geometry of the Barreiras Aquifer, Brazil. BJGEO, v. 49, n. 2, e20170141, 2019. https://doi.org/ 10.1590/2317-4889201920170141
TELFORD, W. M.; GELDART, L. P.; SHERIFF, R. E. Resistivity Methods. In: Applied Geophysics, 2nd Edition, Cambridge Univ. Press, Cambridge, UK, 353-358, 1990. https://doi.org/10.1017/CB09781139167932

WILLIAMS, R. T.; GOODWIN, L. B.; MOZLEY, P. S.; BEARD, B.L.; JOHNSON, C. M. Tectonic controls on fault zone flow pathways in the Rio Grande rift, New Mexico, USA. Geology, 43, n. 8, p. 723-726, 2015. https://doi.org/10.1130/G36799.1 https://doi.org/10.1130/G36799.1 